\title{
Contaminación microbiológica y actividad antimicrobiana del azúcar de caña cristalizado sobre algunos agentes de interés médico en Costa Rica
}

\author{
Verónica Pujol, Jendry Díaz, Evelyn Rodríguez \& María Laura Arias* \\ Facultad de Microbiología y Centro de Investigación en Enfermedades Tropicales (CIET), Universidad de Costa \\ Rica, 2060 San José, Costa Rica; *mlarias@cariari.ucr.ac.cr
}

Recibido 22-II-2006. Corregido 19-VII-2007. Aceptado 31-VIII-2007.

\begin{abstract}
Microbiological contamination and antimicrobial activity of cristalised cane sugar on some medically important microorganisms in Costa Rica. Unrefined cristalised cane sugar, obtained after the filtration and evaporation of sugar cane juice, is a nutritional product of traditional consumption in Costa Rica and other Neotropical countries. It has been used in the topic treatment of infected wounds, with satisfactory results even with some antibiotic-ressistant bacteria. We studied the microbiological quality of 50 commercial samples. The analyses included total aerobic and anaerobic bacteria plate count; aerobic and anaerobic spore count; mold and yeast count; total and fecal coliforms; and presence of Clostridium botulinum. The antimicrobial effect was tested for Staphylococcus aureus (ATCC 25923), S. epidermidis (UCR 2902), Pseudomonas aeruginosa (ATCC 9027), Escherichia coli (ATCC 25922), Salmonella enteritidis (ATCC 13076), Listeria monocytogenes (ATCC 19116) and Aspergillus niger (Asni 06). Most of the samples (76\%) presented counts lower than $100 \mathrm{CFU} / \mathrm{g}$ especially for sporulated forms ( $90 \%$ lower than $20 \mathrm{CFU} / \mathrm{g})$, the mold and yeast count was higher $(38 \%$ higher than $10^{2} \mathrm{CFU} / \mathrm{g}$ ), demonstrating the importance of these microorganisms in the spoilage of the product; $76 \%$ of the samples presented fecal contamination; $C$. botulinum was not isolated with the methodology employed. No inhibitory effect was observed for $A$. niger, but all samples han an inhibitory effect over the other species, especially for P. aeruginosa and S. aureus. Rev. Biol. Trop. 56 (2): 431-437. Epub 2008 June 30.
\end{abstract}

Key words: microbiological quality, antimicrobial activity, bacteria associated with wound infections.

La tapa de dulce, panela o papelón, es el producto obtenido de la filtración y evaporación del jugo de la caña de azúcar (Saccharum officinarum). En Costa Rica y otros países neotropicales, constituye un producto alimenticio de consumo tradicional. Aparte de su uso como endulzante, al ser un producto con alta osmolaridad, ha sido utilizado terapéuticamente en heridas y quemaduras infectadas (Dawson 1996).

El jugo de la caña de azúcar está constituido básicamente por agua y carbohidratos. Estos se encuentran en forma insoluble en agua (la fibra) y en forma soluble (sacarosa, glucosa, fructuosa). Los contenidos de cenizas, lípidos (extracto etéreo) y proteína son despreciables (Asocana 2005).
La obtención de la tapa de dulce se logra en varios procesos (Sedó 2001). El primero de ellos es la molienda de la caña de azúcar, proceso mediante el cual se extrae el jugo de la caña. Posteriormente se realiza una prelimpieza, utilizando decantadores o sedimentadores, cuyo objetivo es eliminar agentes colorantes presentes en la tierra y que se activan con el calor, por lo que deben separarse cuando el jugo de caña está aun frío. El siguiente paso es el calentamiento, donde se evapora cerca del $90 \%$ del agua y se concentra el jugo de caña, hasta obtener el dulce. En esta fase los microorganismos presentes serán destruidos por el calor ya que el producto es sometido a temperaturas de $100{ }^{\circ} \mathrm{C}$ o mayores por $100 \mathrm{~min}$ 
aproximadamente. Posteriormente se clarifica con hidrosulfito de sodio o fosfato monocálcico. Finalmente, se le incorpora aire al producto, de manera que el dulce adquiera porosidad, obteniéndose una estructura compacta la cual es moldeada (Calderón 1988, Sedó 2001). El dulce debe ser empacado a temperatura ambiente y no mientras esté caliente, pues ocurre condensación del vapor de agua en las paredes del empaque, por lo que el agua se podría concentrar en alguna parte de la superficie del producto, lo que favorece su contaminación y deterioro.

En Costa Rica, la producción de la tapa de dulce es parte de la agroindustria rural tradicional (Aymerich et al. 1998, Agüero y Calderón 1999) y hay alrededor de 500 trapiches activos en el país (Aymerich et al. 1998, González et al. 2004). En promedio la producción del dulce en la región central es de 5495.5 toneladas al año (Aymerich y Murillo 1998) y el consumo per cápita del dulce es alrededor de $3.0 \mathrm{~kg}$ al año. Se adquiere en el mercado en diversos tipos de empaque, como bolsas de polietileno transparentes, películas plásticas adheribles, cajas transparentes de poliestireno, entre otras. Estos empaques han dejado de lado la forma tradicional de empacar las tapas de dulce, donde cuatro tapas se envuelven en hojas secas de caña, formando lo que se conoce como una "tamuga" y evitando así la contaminación ambiental del producto (Sedó 2001).

Por otra parte, el azúcar granulada (sacarosa) ha sido usada desde antes de la era cristiana y de manera empírica, para la cicatrización de heridas en seres humanos (Dawson 1996, González et al. 2004) Este tratamiento es conveniente y económico, aunque no es aséptico (Chirife et al. 1983); sin embargo, algunos autores describen las soluciones sobresaturadas de azúcar como antisépticas, no siendo necesarios procesos de esterilización (Herszage et al. 1985, Haddad et al. 2000).

En Costa Rica se ha utilizado la tapa de dulce rallada como alternativa en el tratamiento tópico de infecciones causadas por bacterias resistentes a diversos antibióticos, con resultados satisfactorios. Dado lo anterior, se pretende con el presente trabajo, evaluar la calidad microbiológica de la tapa de dulce costarricense, la presencia de Clostridium botulinum y el espectro de inhibición sobre algunos agentes de importancia médica, a fin de contribuir a valorar el riesgo o beneficio de esta práctica.

\section{MATERIALES Y MÉTODOS}

Muestras: se analizaron 50 muestras de tapa de dulce, provenientes de productores nacionales, adquiridas directamente de los trapiches, en mercados y en supermercados de diferentes zonas del país. Las muestras fueron transportadas al Laboratorio de Microbiología de Alimentos, Facultad de Microbiología.

Calidad microbiológica: se siguió la metodología descrita en el Manual de Microbiología, Food and Drug Administration (1995), para el recuento total de bacterias aerobias y anaerobias, recuento de esporas aerobias y anaerobias, recuento de hongos y levaduras.

De cada muestra se pesó $10 \mathrm{~g}$ y se diluyó en $90 \mathrm{~mL}$ de agua peptonada estéril $0.1 \%$ (APE), homogeneizando en Stomacher ${ }^{\circledR}$. A partir de esta solución se prepararon diluciones decimales hasta $10^{-4}$ en APE.

De cada dilución se inoculó, por duplicado y esparcido, $0.5 \mathrm{~mL}$ en platos de agar estándar + TTC (2, 3, 5 cloruro de trifenil tetrazolium), los cuales fueron incubados a $35^{\circ} \mathrm{C}, 48 \mathrm{~h}$ en aerobiosis para el recuento total aerobio y en anaerobiosis (jarra de anaerobiosis) para el recuento total anaerobio. Se inoculó, además, por duplicado, $1 \mathrm{~mL}$ de cada dilución en placas de agar papa dextrosa acidificado, para el recuento de hongos y levaduras. Las placas se incubaron a temperatura ambiente por cuatro días.

Para el recuento de esporulados, se hizo una ebullición inicial por $5 \mathrm{~min}$ de $10 \mathrm{~g}$ de muestra homogeneizada en $90 \mathrm{~mL}$ de APE. A partir de esta dilución madre, se prepararon diluciones decimales, las cuales fueron inoculadas por duplicado y esparcido en agar estándar + TTC e incubadas igual que en el recuento total aerobio y anaerobio. 
Se determinó el número más probable/g (NMP/g) de coliformes totales y fecales en serie de tres tubos, utilizando caldo lactosado simple como medio de enriquecimiento, caldo verde brillante y caldo Escherichia coli como medios de confirmación (Pouch 2001).

Se evaluó la presencia de $C$. botulinum siguiendo la metodología descrita en Vanderzant y Splittstoesser (Pouch 2001), de manera que 1 g de tapa de dulce se inoculó en cada uno de dos tubos con $15 \mathrm{~mL}$ de medio carne cocida prerreducido y se incubaron a $35^{\circ} \mathrm{C}$ por cuatro días. Uno de ellos fue tratado con calor $\left(80^{\circ} \mathrm{C}\right.$ por $10 \mathrm{~min}$ ) y ambos fueron inoculados en agar yema de huevo e incubados en anaerobiosis a $35{ }^{\circ} \mathrm{C}$ por $48 \mathrm{~h}$.

\section{Determinación de la actividad antimicro-}

biana: se realizaron diluciones de cada muestra de tapa de dulce en APE $0.1 \%$ para obtener concentraciones finales de $75 \%, 50 \%, 25 \%$ y $12.5 \%$ $\mathrm{v} / \mathrm{v}$. Se prepararon suspensiones bacterianas 0.5 McFarland en APE a partir de cultivos de 24 $\mathrm{h}$ en placas de agar sangre de Staphylococcus aureus (ATCC 25923), S. epidermidis (UCR 2902), Pseudomonas aeruginosa (ATCC 9027), E. coli (ATCC 25922), Salmonella enteritidis (ATCC 13076) y Listeria monocytogenes (ATCC 19116). En un lapso no mayor de $15 \mathrm{~min}$ se introdujo un hisopo con algodón, se eliminó el exceso de líquido y se distribuyó uniformemente en tres direcciones sobre la superficie de placas de Agar Muller-Hinton de $4 \mathrm{~mm}$ de grosor, a las cuales previamente se les horadó cinco pocillos. A cada pocillo se le agregó $0.30 \mathrm{~mL}$ del producto concentrado y de cada una de las concentraciones de tapa de dulce previamente descritas. Todas las placas fueron incubadas a 35 ${ }^{\circ} \mathrm{C}$ por $18 \mathrm{~h}$. En aquellas en las que se observó un halo de inhibición del crecimiento bacteriano, se midió el diámetro.

También se evaluó la actividad antimicrobiana sobre $A$. niger, la cual se realizó según el método de difusión mencionado anteriormente con las siguientes modificaciones: la suspensión al 0.5 McFarland se realizó a partir de un filtrado conteniendo únicamente conidias de $A$. niger y la incubación se realizó por cuatro días a temperatura ambiente.

\section{RESULTADOS}

Los resultados de la evaluación de la carga microbiológica de las muestras demostraron que los recuentos totales fueron bajos, tanto para bacterias aerobias como anaerobias, pues el $76 \%$ y el $90 \%$ de las muestras respectivamente presentaron recuentos menores a 100 UFC/g (Cuadro 1). Igualmente, se encontró un bajo recuento de bacterias esporuladas aerobias y anaerobias, más del $90 \%$ de las muestras presentaron recuentos menores a $20 \mathrm{UFC} / \mathrm{g}$ (Cuadro 1). Con respecto a hongos y levaduras, se pudo observar recuentos importantes de hasta $10^{5}$ y $10^{4} \mathrm{UFC} / \mathrm{g}$ para un $12 \%$ y $8 \%$ de las muestras, el $62 \%$ de las muestras presentaron recuentos inferiores a $10^{2} \mathrm{UFC} / \mathrm{g}$.

CUADRO 1

Calidad microbiológica de 50 muestras de tapa de dulce adquiridas en el mercado costarricense

TABLE 1

Microbiological quality analysis of 50 samples acquired in the Costa Rican market

\begin{tabular}{|c|c|c|c|c|c|}
\hline Parámetro & $\begin{array}{l}\text { Recuento } \\
\text { total aerobio }\end{array}$ & $\begin{array}{l}\text { Recuento } \\
\text { total } \\
\text { anaerobio }\end{array}$ & $\begin{array}{l}\text { Recuento } \\
\text { esporulados } \\
\text { aerobios }\end{array}$ & $\begin{array}{l}\text { Recuento } \\
\text { esporulados } \\
\text { anaerobios }\end{array}$ & $\begin{array}{l}\text { Recuento } \\
\text { hongos y } \\
\text { levaduras }\end{array}$ \\
\hline & & $\mathrm{n} \quad \%$ & n $\%$ & $\mathrm{n} \quad \%$ & $\mathrm{n} \quad \%$ \\
\hline$£ 20 \mathrm{UFC} / \mathrm{g}$ & $29(58 \%)$ & $43(86 \%)$ & $45(90 \%)$ & $47(94 \%)$ & $9(18 \%)$ \\
\hline 20-100 UFC/g & $9(18 \%)$ & $2(4 \%)$ & $4(8 \%)$ & $2(4 \%)$ & $31(62 \%)$ \\
\hline$>100 \mathrm{UFC} / \mathrm{g}$ & $12(24 \%)$ & $5(10 \%)$ & $1(2 \%)$ & $1(2 \%)$ & $10(20 \%)$ \\
\hline
\end{tabular}


La evaluación de coliformes demostró que un $82 \%$ (41 muestras), presentó un NMP de coliformes totales/g de 3.0 hasta 460 y un $76 \%$ (38 muestras) contaminación con coliformes fecales de 3.0 hasta 240 .

En ninguna de las muestras se logró aislar C. botulinum, hallazgo que correlaciona con los bajos recuentos de esporulados anaerobios mencionados anteriormente.

En el cuadro 2 se presentan los resultados de la evaluación de la actividad antimicrobiana de varias concentraciones de tapa de dulce sobre el crecimiento de las especies de interés. Una concentración menor de $25 \%$ de tapa de dulce, no mostró halo de inhibición para ninguna de las especies bacterianas estudiadas, demostrándose que conforme se diluye la concentración de tapa de dulce en la muestra, el efecto inhibidor disminuye, pues aumenta el Aw y desciende la osmolaridad, condiciones que se consideran responsables del efecto antimicrobiano. Cabe destacar que todos los microorganismos evaluados, excepto $A$. niger, fueron inhibidos por la tapa de dulce sin diluir (Cuadro 2).

Es importante resaltar los resultados obtenidos con $S$. aureus pues, además de su inhibición en concentraciones de $100 \%$ de tapa de dulce, fue demostrado efecto inhibitorio en concentraciones del $50 \%$ y del $25 \%$ (Cuadro 2). El porcentaje más alto de inhibición total, lo presentó $P$. aeruginosa, $(90 \%$ para la con- centración del 100\%); sin embargo, diluciones inferiores al $50 \%$ no la afectaron.

\section{DISCUSIÓN}

Los datos obtenidos para la evaluación microbiológica de las muestras de tapa de dulce coinciden con lo esperado, dado que éste es un producto cuyo proceso de evaporación involucra exposición a altas temperaturas (superior a $100{ }^{\circ} \mathrm{C}$ por más de $100 \mathrm{~min}$ ) (Sedó 2001) y una baja humedad relativa (menor a $7.9 \%$ ) (Calderón 1988), condiciones que disminuyen considerablemente la población microbiana en el producto terminado.

A pesar de que el porcentaje de humedad de las tapas de dulce es bajo, sobreviven hongos y levaduras, que se han descrito como los principales agentes de deterioro en productos dulces y de alta osmolaridad (Pouch 2001). Por otra parte, hay que tener en cuenta que la presencia de estos microorganismos podría estar subestimada, ya que existen levaduras osmofílicas que necesitan medios con alta osmolaridad para ser aisladas.

Los valores obtenidos para los indicadores coliformes totales y fecales llevan a considerar una posible contaminación postproceso del producto, por condiciones inadecuadas de manipulación del producto terminado para su empacado, lo que es de sumo cuidado

CUADRO 2

Porcentaje de muestras de tapa de dulce que mostraron halo de inhibición sobre el crecimiento diferentes bacterias $(n=50)$

TABLE 2

Proportion of samples that showed inhibition halums on the growth of different bacteria $(n=50)$

$\begin{array}{cccccccc}\begin{array}{c}\text { Concentración } \\ \text { de tapa de dulce } \\ (\% \mathrm{v} / \mathrm{v})\end{array} & \text { S. aureus } & \text { S. epidermidis } & \text { P. aeruginosa } & \text { E. coli } & \text { S. enteritidis } & \begin{array}{c}\text { L. mono- } \\ \text { cytogenes }\end{array} & \text { A. niger } \\ 100 & 86 & 84 & 90 & 78 & 80 & 16 & 0 \\ 75 & 34 & 12 & 22 & 8 & 12 & 4 & 0 \\ 50 & 4 & 0 & 18 & 0 & 0 & 0 & 0 \\ 25 & 2 & 0 & 0 & 0 & 0 & 0 & 0 \\ <25 & 0 & 0 & 0 & 0 & 0 & 0 & 0\end{array}$


considerando que es un producto para consumo directo (Pouch 2001).

Se debe destacar que en ninguna de las muestras se logró aislar $C$. botulinum, no obstante, es importante tomar en cuenta que el método utilizado es poco sensible considerando que la cantidad de estas esporas en la tapa de dulce podría ser muy baja. En Costa Rica, el aislamiento de C. botulinum a partir de suelos ha sido descrito (Gamboa et al. 1993a, 1993b) al igual que en muchos otros países (Nakano et al. 1990, Schocken-Iturrino et al. 1999, Nevas et al. 2002). Estudios japoneses (Kobayashi et al. 1992) en muestras de suelo provenientes de los campos de cultivo de la caña de azúcar, han demostrado la presencia de $C$. botulinum en un $7.2 \%$ de 290 muestras analizadas, principalmente del tipo C (5.9\%). Por tanto, aunque no se encontró esta bacteria en ninguna de las muestras, podría eventualmente estar presente en la tapa de dulce. Se hace necesario entonces algún otro método más sensible, como la Reacción en Cadena de la Polimerasa, para poder detectar esporas de esta bacteria, utilizar algún proceso de concentración para aumentar la sensibilidad o aumentar la cantidad y número de muestras a evaluar (Aranda et al. 1991, Chirife et al. 1983, Nakano et al. 1992).

A mediados de los años 80's se publicaron diversos estudios, tanto in vitro, como in vivo, que confirmaban la actividad antimicrobiana de soluciones concentradas de azúcar (sacarosa) en heridas y quemaduras (Chirife et al. 1983, Cohen 1985, Middleton y Seal 1985, Viau et al. 1985, Briozzo et al. 1989, Grauwin et al. 1999, William 2002, Bowlwe et al. 2001). La tapa de dulce es también un producto con altas concentraciones de sacarosa e igualmente es un producto con una alta osmolaridad y bajo Aw, esperándose una actividad antimicrobiana importante. Los datos obtenidos demuestran una importante actividad contra $S$. aureus y $P$. aeruginosa, patógenos aislados frecuentemente de heridas infectadas, causando problemas principalmente a nivel intrahospitalario por numerosas cepas resistentes a antibióticos (Cohen 1985, González et al. 2005). De manera contraria, no hay una actividad importante contra
A. niger. Aunque el crecimiento bacteriano se ve afectado por el bajo Aw de la tapa de dulce, no es suficiente para alterar el crecimiento de algunos hongos, microorganismos de gran resistencia a este factor (Pouch 2001).

Cabe destacar que los resultados obtenidos con las muestras analizadas corresponden a estudios in vitro. Diversas publicaciones sugieren que las soluciones de sacarosa en heridas, in vivo, favorecen su cicatrización, aumentando el número de macrófagos y de fibroblastos, por mecanismos que no han sido esclarecidos completamente (Cohen 1985, Middleton y Seal 1985, Viau et al. 1985, Grauwin et al. 1999). De esta manera, se vuelve conveniente investigar este aspecto, pues de manera empírica se han observado resultados satisfactorios con el uso tópico de la tapa de dulce. Por otra parte, se abre la posibilidad de realizar estudios que utilicen cepas bacterianas aisladas de heridas infectadas, para evaluar y comparar la actividad antimicrobiana de la tapa de dulce con este tipo de aislamientos. No obstante, debe controlarse la contaminación con coliformes totales y fecales detectada, pues sería contraproducente en el tratamiento tópico de heridas y más bien representaría un punto de infección.

\section{RESUMEN}

La tapa de dulce o panela es un producto alimenticio de consumo tradicional, típico de países neotropicales, obtenido de la filtración y evaporación del jugo de la caña de azúcar. Además de su uso clásico como endulzante, en Costa Rica y otras partes del mundo se ha utilizado para el tratamiento tópico y empírico de heridas infectadas, con resultados satisfactorios, aún en infecciones por bacterias resistentes a diversos antibióticos. A fin de valorar el riesgo o beneficio de esta práctica, se evaluó la calidad microbiológica de 50 muestras de tapa de dulce de producción nacional obtenidas en trapiches, mercados y supermercados. Se realizaron recuentos bacterianos aerobios y anaerobios, de bacterias esporuladas y no esporuladas y de hongos y levaduras, se determinó el número de coliformes totales y fecales, la presencia de Clostridium botulinum y se evaluó el efecto antimicrobiano de este producto sobre algunos patógenos: Staphylococcus aureus (ATCC 25923), S. epidermidis (UCR 2902), Pseudomonas aeruginosa (ATCC 9027), Escherichia coli (ATCC25922), Salmonella enteritidis (ATCC 13076), Listeria monocytogenes (ATCC 19116) 
y Aspergillus niger (Asni 06). La mayoría de las muestras (76\%) presentaron recuentos bacterianos menores de 100 UFC/g, especialmente de esporulados ( $90 \%$ menos de 20 $\mathrm{UFC} / \mathrm{g})$, y recuentos de hongos y levaduras elevados $(20 \%$ mayores a $100 \mathrm{UFC} / \mathrm{g})$. Un alto porcentaje de las muestras presentó contaminación fecal $(76 \%, \mathrm{NMP} / \mathrm{g}$ desde 3 hasta 460). No se logró aislar C. botulinum en ninguna de las muestras. Todas las muestras del producto concentrado desarrollaron halo de inhibición sobre los cultivos, principalmente sobre $P$. aeruginosa y $S$. aureus; pero no se observó ningún tipo de inhibición sobre $A$. niger.

Palabras clave: calidad microbiológica, actividad antimicrobiana, bacterias asociadas a infecciones de piel.

\section{REFERENCIAS}

Agüero, J. \& R. Calderón. 1999. La transmisión intergeneracional de los oficios de cañero y de productor de granos básicos en el mundo rural costarricense (1850-1960). Anuario de Estudios Centroamericanos, Universidad de Costa Rica 25: 111-138.

Aranda, E., M.M. Rodríguez, M.A. Asensio \& J.J Córdoba. 1997. Detection of Clostridium botulinum types A, B, E and F in foods by PCR and DNA probe. Lett. Appl. Microbiol. 25: 186-190.

Aymerich, S., J. Cordero \& F. Sedó. 1998. Lineamientos de Políticas. Consejo Nacional de Producción, San José, Costa Rica.

Aymerich, S. \& O. Murillo. 1998. Guía de instalación de plantas procesadoras de dulce de caña de azúcar: instalaciones físicas, requisitos sanitarios y buenas prácticas de manufactura. Consejo Nacional de Producción, San José, Costa Rica.

Bowlwe, P.G., B.I. Duerden \& D.G. Armstrong. 2001. Wound microbiology and associated approaches to wound management. Clin. Microb. Rev. 14: 244-269.

Briozzo, J., L. Nuñez, J. Chirife \& L. Herszage. 1989. Antimicrobial activity of clover oil dispersed in a concentrate sugar solutions. J. Appl. Bacteriol. 66: 69.

Calderón, A. 1988. Evaluación físico-química del proceso de elaboración de dulce de tapa o panela. Tesis de licenciatura, Ciudad Universitaria Rodrigo Facio, Universidad de Costa Rica, San José, Costa Rica.

Chirife, J., L. Herrszage, A. Joseph \& E. Kohn. 1983. In vitro study of bacterial growth inhibition in concentrated sugar solutions: microbiological basis for use of sugar in treating infected wounds. Antimicrob. Agents Chemother. 23: 766-773.

Cohen, M. 1985. Topical treatment of pressure sores. Hosp. Pharm. 20: 451-457.

Dawson, J.S. 1996. The role of sugar in wound healing. A comparative trial of the healing of infected wounds using traditional gauze/antiseptic packing and granulated sugar, undertaken during an elective period at Kagando Hospital, Uganda. Ann. R. Coll. Surg. Engl. 72: $82-85$.

Food and Drug Administration. 1995. Bacteriological analytical manual. AOAC Int., Washington, EEUU.

Gamboa, M., E. Rodríguez \& B. Fernández. 1993a. Primer aislamiento de Clostridium botulinum en Costa Rica. Rev. Biol. Trop. 41: 285-286.

Gamboa, M., E. Rodríguez \& B. Fernández. 1993b. Clostridium botulinum en suelos de Costa Rica. Rev. Biol. Trop. 41: 359-363.

González, H., R. Rodríguez, M. Machado, J. González \& J. Cabrera. 2004. Heridas. Métodos de tratamiento. Medisan 8: 33-42.

Grauwin, M.L.Y., J.L. Cartel \& J.P Lepers. 1999. Honey does one treat the osteitis and osteoarthritis of the extremities in older leprosy patients using granulated table sugar. Acta Leprol. 11: 147-152.

Haddad, M., L.C. Bruschi \& E.A. Martins. 2000. The effect of sugar on the process of cicatrization of infected surgical incisions. Rev. Lat. Am. Enfermagem. 8: 57-65.

Herszage, L., R. Rovere, C. Grassi, J. Baena, E. Niño \& J. Paredes. 1985. Conservación de tejidos por deshidratación con soluciones sobresaturadas de sacarosa y su rehidratación. Sem. Méd. 166: 5327.

Kobayashi, T., K. Watanabe \& K. Ueno. 1992. Distribution of Clostridium botulinum and Clostridium tetani in Okinawa Prefecture. Kansenshogaku Zasshi 66: 1639-44.

Middleton, K.R. \& D. Seal. 1985. Sugar as an aid to wound healing. Pharm. J. 235: 757-758.

Nakano, H., T. Okabe, H. Hashimoto \& G. Sakaguchi. 1990. Incidence of Clostridium botulinum in honey of various origins. Jpn. J. Med. Sci. Biol. 43: 183-195.

Nakano, H., Y. Yoshikuni, H. Hashimoto \& G. Sakaguchi. 1992. Detection of Clostridium botulinum in natural sweeting. Int. J. Food Microbiol. 16: 117-121. 
Nevas, M., S. Hielm, M. Lindstrom, H. Horn, K. Koivulehto \& H. Korkeala. 2002. High prevalence of Clostridium botulinum types A and B in honey samples detected by polymerase chain reaction. Int. J. Food Microbiol. 72: 45-52.

Schocken-Iturrino, R.P., M.C. Carneiro, E. Kato, J.O. Sorbara, O.D. Rossi \& L.E. Gerbasi. 1999. Study of the presence of the spores of Clostridium botulinum in honey in Brazil. FEMS Immunol. Med. Microbiol. 24: 379-382.

Sedó, F. 2001. Manual de producción de dulce. Consejo Nacional de la Producción, San José, Costa Rica.

Pouch, 2003. Compendium of methods for the microbiological examination of foods. American Public Health Association, Washington, EEUU.
Viau, F., D. Mangenot, C. Boval \& J. Perron. 1985. Treatement des escarres par le sucre cristallisé du commerce. Presse Médicale 14: 14.

William, M. 2002. Honey and Wound Healing. J. Wound, Ostonomy \& Continence Nursing 29: 295-300.

\section{REFERENCIAS INTERNET}

González, C., J. García, J. Martínez, M. Sánchez \& C. Alcón. Multifuncionalidad del azúcar blanca de mesa en la cicatrización de las heridas (consultado: julio 2005, http://es.geocities.com/carlosgerena/sevilla).

ASOCANA. 2005. Historia de la caña de azúcar (consultado: julio 2005, http://www.asocana.com.co/historia. asp). 